Revista de Indias, 1997, vol. LVII, núm. 211

\title{
EL OTRO ES UNO: PUERTO RICO EN LA MIRADA NORTEAMERICANA DE $1898^{1}$
}

POR

\author{
GERVASIO LUIS GARCÍA
}

Universidad de Puerto Rico, Río Piedras

Repesar el 98 en Puerto Rico supone alejarse de planteamientos victimistas que eximen de toda responsabilidad al pueblo puertorriqueño. El 98 es abordado en este trabajo como un año de liberación y dominación, en el que se valoran los aspectos positivos y negativos del imperialismo norteamericano, a la vez que se analizan críticamente las luchas, desiguales y singulares, de este pueblo por la justicia social y económica, la cultura y las libertades políticas. El pensamiento de Elihu Root y Salvador Brau ilustran parte de este proceso.

«Antes de que le sea confiado el autogobierno, el pueblo de Puerto Rico tiene que aprender la lección del autocontrol y el respeto a los principios del gobierno constitucional, que requiere la aceptación de sus pacíficas decisiones...»

Elihu Root, Secretario de la Guerra de los Estados Unidos

«Como el tiempo solamente puede modificar las costumbres, acaso hubiera sido conveniente la prolongación del régimen militar [norteamericano] para moderar la brusca transición del viejo régimen colonial a los amplios métodos democráticos, acostumbrand así a la masa popular a no confundir las prácticas de la libertad con el desenfreno de la licencia...»

Salvador Brau, historiador puertorriqueño

1 Agradezco profundamente las sugerencias bibliográficas de Juan A. Giusti Cordero y las lecturas críticas de María de los Ángeles Castro Arroyo y Georg H. Fromm. 
Conquistador y conquistado se miran y se hacen cómplices en el 98 puertorriqueño. Después vienen las voces discordantes, y los polos opuestos unidos se separan y se tocan intermitentemente, al vaivén de las conveniencias y las necesidades inmediatas. Las afinidades de Elihu Root, ejecutor de la política militar y colonial de los Estados Unidos a fin de siglo, y de Salvador Brau, ilustrado criollo autonomista y el intelectual más sobresaliente de su generación, sugieren que los significados de la invasión norteamericana $-\mathrm{y}$ de nuestra larga relación con otros grandes centros de atracción como Inglaterra y Francia- no pueden precisarse en toda su espesura si nos quedamos atrapados en la creencia de que el Otro (o la Otra) y yo son antípodas con miradas e intereses irreconciliables que, además, hablan, cada uno, con una sola voz. La coincidencia de Root y Brau en que lo moral es el principal obstáculo a la democratización del país, como dicen en el epígrafe de este ensayo, apunta en otra dirección.

\section{CIVILIZACIÓN Y BARBARIE A LA ROOT}

Elihu Root (1845-1937), exitoso abogado corporacionista de Nueva York, Secretario de la Guerra (1899-1904) y posteriormente Secretario de Estado (1905-1909), fue el principal defensor de la política del «patrician tutelage» y la «asimilación benevolente» de los nativos ${ }^{2}$. Se asentaba en la ocurrencia de que los puertorriqueños no fueron educados en el «arte del autogobierno o del gobierno verdaderamente honesto». Según Root, en la tradición y la experiencia puertorriqueñas la ley y la libertad estuvieron encontradas y divorciadas. Por lo tanto, «... es imposible que una gente con esta historia - sólo el diez por ciento sabe leer y escribir - pueda tener una comprensión real de la manera de conducir un gobierno popular» ${ }^{3}$.

El Secretario de la Guerra no cuestionaba la capacidad de aprendizaje de los boricuas, atestiguada por la minoría masculina bien

\footnotetext{
2 En su hoja de vida destaca, además, la autoría de la Enmienda Platt (1902), que hizo de Cuba un «protectorado» norteamericano, y de la Guardia Nacional (1903). Thomas G. PATERSON et al., American Foreign Policy. A History to 1914. 3rd. ed., Massachussetts, D. C. Heath \& Co., 1988, pp. 224-225, 227; Julius. W. PRATT, A Histiry of the United States Foreign Policy. New York, Prentice Hall, 1955, p. 27.

3 Elihu Root, The Military and Colonial Policy of the United States. Addresses and Reports., Cambridge, Harvard University Press, 1924, pp. 163-4. La traducción es mía.
} 
educada y capaz, con conciencia pública y política. Pero creía que el pequeño grupo era insuficiente para integrar un gobierno y, por consiguiente, actuaría como una oligarquía. El problema no era únicamente el desconocimiento de los métodos y prácticas de gobierno (algunos sólo con un mero conocimiento teórico) sino la tara moral de que los puertorriqueños, como pueblo, «nunca aprendieron a obedecer la decisión de la mayoría». La experiencia fresca de las primeras elecciones municipales bajo el gobierno norteamericano, le mostró al propulsor de la Enmienda Platt, que la minoría derrotada se negaba siempre a continuar participando en los asuntos de gobierno. Es decir, éramos malos perdedores, defecto que compartíamos con los antillanos y los centroamericanos - todos en la «misma latitud»sumidos en continuas revoluciones ${ }^{4}$.

Por lo tanto, los puertorriqueños estaban en una etapa rudimentaria del desarrollo político y necesitaban un período de lento aprendizaje para lograr el autocontrol y el respeto a los principios constitucionales. En esencia, no era una cuestión de falta de talento intelectual sino de «carácter y de hábitos de pensar y sentir». Disminuidos a la escala de subdesarrollados políticos y morales, se justificaba entonces una tutoría colonial de «mano fuerte y orientadora» 5 .

\section{EL SUAVE PATERNALISMO CRIOLLO}

Tal vez Salvador Brau (1842-1912) nunca leyó el Report de 1899 de Mr. Root y seguramente no compartió los extremos de su visión imperialista, pero coincidió con él en la poca fe en los «elementos insulares» para el gobierno propio a corto plazo. De ahí su exaltación del gobierno militar norteamericano (1898-1900) por el «espíritu expansivo y los respetos individuales que honran a la Constitución de los Estados Unidos» ${ }^{6}$. Al hacer el balance positivo del interregno castrense, Brau destaca en primer plano la enseñanza obligatoria, impresionado por el esparcimiento de las escuelas «por todas partes». Su esperanza era que el régimen militar suavizara, me-

4 Ibid., pp. 164-5.

5 Ibid.

6 Salvador BraU, Historia de Puerto Rico. Reimpresi;on facsimilar, San Juan de Puerto Rico, Editorial Coquí, 1966, p. 305. La primera edición es de 1904.

R. I., $1997, \mathrm{n}^{\circ} 211$ 
diante la educación, el salto del viejo régimen al sistema democrático, «acostumbrando así a la masa popular a no confundir las prácticas de la libertad con el desenfreno de la licencia...» ${ }^{7}$

Para el historiador caborrojeño, los militares yanquis implantaron una reforma «trascendental»:

El derecho de reunión, asociación y manifestación, la libertad de imprenta y el ejercicio de todos los cultos no tuvieron cortapisas. Suprimióse con la Diputación Provincial la lotería, lo mismo que el papel sellado de toda clase, las cédulas de vecindad y las riñas de gallos, que constituían arbitrios; establecióse la jornada de ocho horas para el trabajo obrero; reorganizóse la administración judicial, simplificando procedimientos, aboliendo la prisión por sospechas y suprimiendo cepos, grillos y cadenas en los establecimientos penales; creóse un cuerpo de policía insular, para servicios urbanos y rurales, cuyas plazas y oficialidad se confiaron a hijos del país; formáronse dos regimientos, uno de infantería y otro de caballería, con oficialidad americana, en que se demostraron una vez más las aptitudes militares de los puertorriqueños... ${ }^{8}$

Sensible a estos progresos (a los que sumó la reorganización de los servicios, la sanidad en particular), Brau lamentó la partida de los gobernantes militares porque los efectos de sus reformas «...necesitan tiempo para manifestarse en toda su plenitud y como el tiempo solamente puede modificar las costumbres, acaso hubiera sido conveniente la prolongación del régimen militar...»9

Al convenir Brau con Root, no estamos ante el caso del vulgar traidor de las historias nacionalistas que reducen el valor individual y colectivo a la concentración de patriotismo en la sangre, otra manera equivocada de recurrir a la moral para explicar realidades complicadas y variables. Es, en realidad, el dilema del hijo de la colonia entre imperios, estudiado por Arcadio Díaz Quiñones: «El sujeto subalterno colonial está dominado por el discurso del Otro, y en su imaginario la autonomía requiere la referencia al poder externo, a la Ley de la Historia. Quizás por ello para muchos autonomistas los

7 Ibid., pp. 309-10.

8 Ibid., pp. 305-6.

9 Ibid., pp. 309-10.

R. I., $1997, \mathrm{n}^{\circ} 211$ 
orígenes "civilizados" españoles fueron perfectamente compatibles con el nuevo poder norteamericano.» ${ }^{10}$

En la legitimación de ambas dominaciones, Brau no sólo apuesta a las bondades civilizadoras de los norteamericanos sino que revela que su mirada (como la del resto de la elite propietaria, profesional e intelectual, empeñada en retener o escalar el menguado poder político y social) estaba más en sintonía con la de los poderosos invasores que con los peones y campesinos y los trabajadores urbanos. Disipado el humo de los cañones y callados los ruidos de la retórica ibérica después de la derrota, el conquistador se torna en aliado del criollo frente a las clases peligrosas que pueden confundir la libertad con el «desenfreno de la licencia».

Si lo anterior es cierto, entonces el estudio comparado de retóricas y visiones imperiales y subalternas es legítimo si toma en cuenta, por lo menos:

1. el original imperialismo de marca norteamericana;

2. la pluralidad de voces de los dominadores;

3. el país real, es decir, la guerra antes de la guerra del 98, que lleva a los grupos sociales a distanciarse entre sí y a alinearse de antemano con el futuro dominador ${ }^{11}$;

4. la semejanza en la diferencia y la complicidad en la dominación son caras de una misma realidad, pero no niegan la capacidad liberadora de los súbditos. En otras palabras, el adversario superior nos contamina al imponernos los temas del debate o del combate, pero a la vez nos impulsa a superar sus imposiciones.

\section{UN IMPERIO SIN COLONIAS}

«Hacia 1900 los proyectos colonizadores no estaban lastrados por una aureola desfavorable... Uno llevaba el progreso y la civilización a las poblaciones mas o menos atrasadas, desalojándolas o subordinándolas...»

Maxime Rodinson

\footnotetext{
10 Arcadio DíAz QuiÑonES, «Salvador Brau: la paradoja de la tradición autonomista». La Torre (Nueva Época), año VII, núms. 27-28, p. 414. El subrayado es del original

11 Ver la versión desmitificadora del conflicto posterior a la guerra en Fernando PICO, 1898: La guerra después de la guerra. Río Piedras, Ediciones Huracán, 1987.
} 
Entre siglos, la expansión colonial todavía no estaba desprestigiada. De 1870 a 1890 Gran Bretaña amasó 4,7 millones de millas cuadradas; Francia controló 3,5 millones y Alemania, la última en llegar a la carrera imperialista, se resignó a poseer sólo un millón de millas cuadradas. Los Estados Unidos apenas sumaron $125.000 \mathrm{mi}$ llas cuadradas. En 1901 existían en el planeta 140 colonias, llamadas también «protectorados», «dependencias», «territorios», «posesiones» y después de la Primera Guerra Mundial, «mandatos», sin contar las «áreas de influencia». Todas ocupaban dos quintas partes de la superficie del globo en la que existía una tercera parte de la población mundial (unos 500.000.000 habitantes). Tres cuartas partes de los colonizados vivían en los trópicos y todos los imperios tenían climas templados. Además, las tierras ocupadas compraban el 40 por ciento de los productos importados en sus madres patrias y otro tanto de su producción era exportado a las sedes imperiales ${ }^{12}$. Entonces «en el océano global todos los [grandes] estados eran tiburones y todos los estadistas lo sabían ${ }^{13}$.

Frente a los escualos europeos, los Estados Unidos parecían rezagados antes del 98. Hasta esa fecha, todos sus territorios conquistados estaban en el continente norteamericano, salvo las islas Midway (1867) en el Pacífico, que servían de carboneras y de enlace de las comunicaciones telegráficas. En esa empresa, las experiencias acumuladas en las guerras de la segunda mitad del siglo XIX contra los native americans (1870-1890) fueron decisivas. Así, el gobierno federal dejó de considerar a los diferentes grupos indígenas como naciones aparte y a partir de 1871 los expulsó de las tierras deseadas, los aisló en reservaciones y los trató como comunidades locales dependientes. En las últimas tres décadas del siglo, los blancos ocuparon más tierras que en los trescientos años anteriores. Y lo lograron mediante la organización de un poderoso ejército, considerado como uno de los mejores de la época por sus éxitos militares contra los nativos americanos. En esos combates fue que el general Nelson

12 O. P. Austin, Colonial Administration, 1800-1900. Methods of Government and Developement Adopted by the Principal Colonizing Nations in their Control of Tropical and Other Colonies and Dependencies. Washington, Government Printing Office, 1901, p. 1464; David K. FiELDHOusE, Los imperios coloniales desde el siglo XVIII. Trad. de Agustín Gil Lasierra, México, Siglo Veeintiuno Editores, 1984, p. 126.

13 Eric HoBSBAwm, The Age of Empire, 1875-1914. New York, Pantheon Books, 1987, p. 318.

R. I., $1997, \mathrm{n}^{\circ} 211$ 
A. Miles (jefe principal en la guerra del 98 contra España) afinó sus artes marciales y potenció su prestigio ${ }^{14}$. Al estallar las primeras escaramuzas en Filipinas (1898-1902), el 87 por ciento de los generales norteamericanos que combatieron las guerrillas habían participado en las luchas contra los indígenas norteamericanos. Pero más importante para el desarrollo del imperio fue que «los nuevos términos legales inventados después de 1870 para controlar los nativos americanos y arrebatarles muchos de sus derechos fueron simplemente trasladados a los asuntos cubanos, filipinos y puertorriqueños después de 1898. Las guerras indias posteriores a 1870 fueron un eslabón clave entre la expansión territorial blanca hasta 1860 y su nuevo imperio ultramarino apropiado en 1898 y posteriormente» ${ }^{15}$.

A partir del 98, los Estados Unidos no pudieron retraerse de «la carrera internacional por la grandeza» y armaron su imperio colonial. La guerra de Cuba acabó con los escrúpulos aislacionistas prevalecientes en su política exterior y los llevó a Filipinas, Guam y las islas Marianas. En el mismo 98, Hawaii fue incorporada a la Unión; la isla Wake (1899) fue anexada para unir a Honolulú con Guam, y se repartió las Samoa con Alemania. Las Tutuiles (1900) y otras islas también pasaron a su posesión. Además, proclamaron su política de puertas abiertas en la China (1899-1900) donde mediante un acuerdo de caballeros con Inglaterra, Francia y Alemania, se repartieron el territorio en áreas de influencias ${ }^{16}$.

En los años siguientes, Estados Unidos ayudó a Panamá a acelerar su separación de Colombia y en 1904 los panameños les cedieron parte de su territorio para construir un canal y firmaron un tratado de protección. En ese mismo año Teodoro Roosevelt, a la sazón presidente de los Estados Unidos, proclamó el derecho a intervenir «en cualquier estado política o económicamente inestable». De segundo plato, mandaron sus soldados a enderezar las finanzas o poner orden en Cuba (1903), República Dominicana (1904-1916), Haití (19151916) y Nicaragua (1911-1916). En 1917 redondearon el imperio

\footnotetext{
14 Benjamin R. BEEDE, ed., The War of 1898 and U.S. Interventions, 1898-1934. An Encyclopedia. New York, Garland Publishing Inc., 1994, p. 454.

15 Walter LA FeBER, The American Age. United States Foreign Policy at Home and Abroad since 1750. New York, W. W. Norton \& Co., 1989, pp. 158-61. BEEDE llega a una conclusión similar [14], p. IX.

16 R. Jackson WILSON et al., The Pursuit of Liberty. A History of the American People. California, Wadsworth Publishing Co., 1990, p. 813.
} 
comprando las Islas Vírgenes a Dinamarca. En un abrir y cerrar de ojos histórico, «los Estados Unidos habían adquirido... un imperio que se extendía por dos océanos y estaba formado en parte por verdaderas posesiones y en parte por estados protegidos» ${ }^{17}$.

La contribución de los Estados Unidos a la historia del colonialismo moderno residió en que construyeron constitucional y semánticamente un imperio sin colonias. Sus conquistas eran «territorio incorporado» en vías de ser estado (Hawaii) o «no incorporado» (Puerto Rico) cobijados por los principios de la Constitución. Estos territorios fueron integrados sin cortapisas al mercado norteamericano. De la misma manera que España juró que no tenía colonias sino provincias, los Estados Unidos confeccionaron un imperio sin objetos ni sujetos coloniales en el que Puerto Rico encajó incómodamente, obligándolos a crear la pudorosa ficción jurídica de «territorio no incorporado», poseído pero separado del lecho del tutor imperial.

Embrollados en el desbocado frenesí expansionista de fines de siglo, los Estados Unidos exhibieron incertidumbres y tribulaciones imperiales. Saltaba a la vista que los principios democráticos (la igualdad y el derecho a la felicidad, por ejemplo) no casaban con la captura de territorios y la sujeción de sus moradores ${ }^{18}$. La tensión entre las ideas republicanas y la práctica imperial, obligó a los responsables de la política exterior norteamericana - con el presidente William McKinley (1843-1901) a la cabeza, y otros grupos opinantes- a sopesar sus dudas sobre las grandes consecuencias de la conquista de territorios no contiguos.

Antes del 98, McKinley favorecía la expansión y el imperio sin guerras y el fin del conflicto de Cuba (1895-1898) sin la intervención militar norteamericana ${ }^{19}$. Al principio se negó a pelear con España porque el pleito podía desembocar en la anexión de Cuba, es decir, en la incorporación de un pueblo con grandes capas negras. Además, temía que la Constitución se desgarraría si se extendía fuera de las costas norteamericanas ${ }^{20}$. Pero los tenaces independentistas cubanos y los testarudos españoles agudizaron la guerra (perjudicando

\footnotetext{
17 FIELDHOUSE [12], pp. 277-9.

18 Ibid., p. 277.

19 WILSON [16], pp. 197-8.

20 LA FEBER [15], p. 185.
} 
de paso las grandes inversiones azucareras de los norteamericanos) y los Estados Unidos recurrieron a la intervención militar.

Cuba, Filipinas y Puerto Rico alimentaron ondas cavilaciones políticas, raciales y constitucionales. Frente a Cuba, McKinley barajó tres alternativas: independencia, anexión o control informal. De entrada descartó la independencia inmediata por su desconfianza de los revolucionarios cubanos, rechazó la anexión por los peligros insospechados de sumar nuevos sectores negros a la Unión y, finalmente, favoreció el dominio indirecto a través de la Enmienda Platt (que le daba derecho a intervenir en Cuba para asegurar la estabilidad interna), incorporada a la Constitución cubana ${ }^{21}$.

En Filipinas, la guerra no cesó con la derrota de España (mayo 1898) pues los filipinos no aceptaron la democracia forzada de los norteamericanos. Por consiguiente, los Estados Unidos enfrentaron una sangrienta guerra de guerrillas que nunca previeron. Los relatos de estremecedoras masacres perpetradas contra la población civil por los soldados yanquis, dividieron agriamente la opinión oficial y general norteamericanas. En mayo del 98, el presidente McKinley - político de profundas creencias religiosas - no sabía qué hacer y ante la indecisión rezó en busca de «luz y orientación del Señor de las naciones». Inspirado, concluyó que los Estados Unidos debían tomar las islas y educar y cristianizar a los filipinos. Pero la resistencia de los isleños no cesó y 19 años después, el Acta Jones (1917) les prometió la independencia si lograban un gobierno estable 22 .

\section{PUERTO RICO, WHAT'S IN A NAME?}

En Puerto Rico, los norteamericanos pasaron más trabajo definiéndonos y organizándonos política y culturalmente que derrotando a los españoles y sus simpatizantes en el campo de batalla. El general Miles fue víctima de su sagacidad militar, pues al despachar sin grandes retos el asunto bélico, un mes después del desembarco, perdió la oportunidad de alcanzar la gloria que sólo se logra en difíciles y sangrientos combates ${ }^{23}$. Pero sus coterráneos, más inclinados a redac-

\footnotetext{
21 Ibid., pp. 185 y 196.

22 WILSON [16], pp. 782, 787-8, 792-5, 799.

23 BEEDE [14], p. 454.
} 
tar el menú colonial, en círculos oficiales y extraoficiales, debatieron sin cuartel hasta sobre cómo llamarnos ¿Porto Rico o Puerto Rico?

A primera vista parecía una insignificante refriega verbal iniciada en 1899 por el geólogo Robert T. Hill al utilizar «Porto Rico» en un artículo publicado en el National Geographic, a pesar de los consejos y la política editorial de la revista, expresados en una coletilla añadida al escrito de marras ${ }^{24}$. Los editores de la revista accedieron a regañadientes ante su insistencia «in this triflling matter», pero aclararon que ello no sentaría precedente. Su posición era clara: Puerto Rico es «utilizada por la gente de la isla y por otros países de lengua española y es buen español». Además, suscribieron la directriz del U.S. Board on Geographic Names (creado por el presidente Benjamin Harrison en 1890) de «adoptar para otros países los nombres por los que los conocen sus habitantes».

La discusión del tema en tres números de la revista sugiere que no se trataba de una excentricidad nórdica cualquiera. Hill, funcionario del United States Geological Service, se defendió rechazando la autoridad del U. S. Board on Geographic Names en materia de ortografía. Subrayó que cuando el Board tomó la decisión de usar «Puerto Rico» en los mapas y documentos oficiales, la isla era territorio extranjero y su nombre no aparecía con frecuencia en los documentos del gobierno y en la literatura. Mas su argumento central residía en que «Porto Rico» se usó internacionalmente por trescientos años, amén de ser de uso común desde la conquista de América por los mejores escritores ingleses y por los mejores geógrafos de los principales países europeos. Además, recurrió a las «leyes de la evolución lingüística»: «Porto» estaba en sintonía con la escritura fonética mientras «Puerto» es «impronunciable en inglés» ${ }^{25}$.

El National Geographic ripostó con ironía universal: fue a «Puerto Rico» donde el Departamento de Estado despachó sus mensajes al estallar la guerra con España. Fue un mapa de «Puerto Rico» el divulgado por la división militar del Departamento de la Guerra y un boletín sobre el comercio con «Puerto Rico» fue publicado por el Departamento de Agricultura seis semanas antes de que España

\footnotetext{
24 Robert T. HILL, «Porto Rico», The National Geographic Magazine, vol. X, núm. 3, March 1899, p. 112.

${ }_{25}$ R. T. HILl, «Porto Rico or Puerto Rico?», The National Geographic Magazine, vol. X, núm. 12, December, 1899, pp. 516-7.
}

R. I., $1997, \mathrm{n}^{\circ} 211$ 
aceptara los términos del tratado de paz dictado por el presidente McKinley. Para evitar la confusión y la inconsistencia, los editores reafirmaron el uso de los nombres autóctonos en vista de que la razón de ser de la revista era la divulgación del conocimiento geográfico con precisión y consistencia, sobre todo en los artículos que hablaban de las «regiones menos conocidas del mundo cuyos nombres geográficos todavía estaban en etapa formativa» ${ }^{26}$.

Más alarmado por las consecuencias culturales y políticas de los argumentos de Mr. Hill, E. W. Hilgard, de la Universidad de California terció en el duelo. Para Hilgard la cuestión debía resolverse rápidamente a partir de unos criterios «racionales y permanentes», antes de que fuera moneda común entre los turistas y los periódicos que hacían las veces de la autoridad en la pronunciación de nombres geográficos de países «cobijados últimamente por la bandera norteamericana». Rechazó, para empezar, que «Puerto» era antifonético e impronunciable, pues le parecía un contratiempo imaginario en vista de que, por ejemplo, California tenía nombres más complicados que eran pronunciados correctamente por los norteamericanos. Si alguno se confundía al expresar nombres en español, ello mostraba la necesidad de reformar el «English spelling» en vez de enunciarlos mal.

En «nuestras posesiones», argumentaba Hilgard, no debe cometerse el mismo error de los ingleses en la India, donde mutilaron los nombres autóctonos; por el contrario, debe imitarse la práctica de los misioneros de Nueva Inglaterra en Hawaii. De manera «sencilla y sensible» éstos adoptaron para los sonidos de las vocales las letras que los representaban consistentemente en los diferentes idiomas. Así se fomentó la comprensión popular de la pronunciación fonética. Abogó entonces por una postura lingüística a la par con las necesidades imperiales, pero sin llegar al nacionalismo desbocado.

Con la enseñanza de más idiomas en nuestras escuelas, para estar a tono con los requisitos de nuestras adquisiciones territoriales e, igualmente, del comercio panamericano, nuestra gente pronto utilizará su sentido común práctico... y descubrirá que lo que ha sido posible en California y Hawaii puede serlo en toda la Nación... Confío en que... la política del Geographic Board de conservar hasta donde sea posible la

26 J. H., «The National Geographic Magazine and the U.S. Board on Geographic Names», Ibid., pp. 517-9.

R. I., 1997, $\mathrm{n}^{\circ} 211$ 
pronunciación y la ortografía nativa de los nombres, sea sostenida como el único medio de evitar la desacreditada y chocante mescolanza de nuestros mapas y documentos oficiales y el agravamiento indefinido que el mal del unprogressive jingoism, inglés o americano, nos impondría y, especialmente a la posteridad ${ }^{27}$.

Ese temor fue confirmado un año antes (algo seguramente desconocido por Hilgard) en las páginas del libro Our Islands and their People, por José De Olivares, oriundo de California.

There are but few historical instances wherein the language of the vanquished nation was adopted by the conqueror. Puerto Rico is unAmerican as well as harsh and affected when the effort is made to pronounce it by anyone unfamiliar with the Spanish tongue. Moreover, we prefer all things American without the least taint or colori:ng of Spanish, and therefore in spite of the Honorable Society and the Government Printers at Washington, we shall adhere to the plain American style in spelling the name of this beautiful insular possession ${ }^{28}$.

Nombrar era una forma de dominar, de apropiarse hasta del nombre de la isla para una mejor digestión imperial.

En 1928 Antonio S. Pedreira retomó la controversia. Recordó que ocho años antes el Geographic Board revocó su posición original y prefirió Porto Rico a Puerto Rico y que, al igual que cuando el exabrupto de Hill (1899), los puertorriqueños «no tomaron cartas en el asunto, ni se contó con ellos luego para sancionar o rechazar esa forma arbitraria e injustificada... ${ }^{29}$

27 E. W. HILGARD, «Geographic Nomenclature», The National Geographic Magazine, vol. XI, núm 1, January, 1900, pp. 36-7. A renglón seguido, uno de los editores de la revista notificó, ingenuamente, que la controversia fue cerrada por el mismo presidente de los Estados Unidos quien decidió, que «Puerto Rico» era el nombre oficial, por ser utilizado «por el mismo presidente de los Estados Unidos quien decidió que «Puerto Rico» era el nombre oficial, por ser utilizado «por el mismo pueblo de la isla». Jubiloso, exaltó el «rico legado de los nombres españoles tan «euphonius» y tan llenos de sentido...» J. H., «Puerto Rico, not Porto Rico, Ibid., pp. 37-8.

28 William S. BRYAND, ed., Our Islands and their People ad Seen With Camera and Pencil. New York, N. D. Thompson Publising Co., 1899, 2 vols., I, p. 265.

29 Antonio S. PEDreira, «De los nombres de Puerto Rico», Aristas. Río Piedras, Editorial Edil, 1969, p. 135. El artículo se publicó por primera vez en 1928. Según Pedreira, la única oposición conocida fue la de José Julio Henna, Manuel Zeno Gandía y Eugenio María de Hostos en 1899 cuando repudiaron las «formas híbridas Porto Rico y Porto Rican». En 1930 el Senado y la Cámara de Representantes de Puerto Rico aprobaron una resolución que

R. I., $1997, \mathrm{n}^{\circ} 211$ 


\section{UN IMPERIO SIN MODELO}

Tan vacilantes y polémicos eran los norteamericanos en la ortografía colonial como inexpertos en el arte de dominar gentes de etnias distintas, en territorios alejados de su plataforma continental. Por lo tanto, tantearon, inventaron e improvisaron sistemas de gobierno y prácticas económicas, a la vez que afirmaron y afinaron su derecho a mandar y disponer de tierras y poblaciones ajenas. Enfrentados a esa inmensa tarea, saltó a primera vista que tenían en sus manos un imperio sin modelo. Ante ese molestoso problema, necesitado de apremiantes soluciones, O. P. Austin publicó su Colonial Administration... (1901), una impresionante recopilación de las experiencias comparadas en el dominio a distancia de España, Holanda, Inglaterra y Francia ${ }^{30}$.

La obra de Austin, jefe del Negociado de Estadísticas del Departamento del Tesoro de los Estados Unidos, es, en verdad, un gran catálogo del buen imperialista, en el que se exponen las causas de los éxitos y los fracasos coloniales y los requisitos para tratar con provecho las gentes de «territorios no contiguos». El autor aspiraba a aprovechar las discusiones derivadas de largos años de estudios y experiencia práctica en la colonización, es decir, presentar «in a single view what may be termed the world's best judgement of today's requirements in the government of a people differing in race, characteristics and climatic environment from that of the governing people.... ${ }^{31}$ En otras palabras, los colonial studies ya tenían un impresionante lugar propio, digno de ser respetado y aprovechado por los gobiernos.

The methods by which colonies are and should be governed and developed are followed and studied with great interest not only by those charged with the government of colonies but by the people of the countries having colonies. [...] The result of this is both stimulating and enlightening to the officers whom the Government intrusts with the duty of developing and caring for the colonies. Colonial associations, colonial institutes, colonial periodicals, colonial books, and colonial li-

\footnotetext{
le pedía al Congreso norteamericano «la restitución oficial del verdadero nombre de esta isla». Ibid., pp. 138-9.

30 Austin [12], p. 1199.

31 Ibid.
} 
braries, and discussions of colonial matters, both in the deliberative and legislative bodies and in the public press, present the various phases of colonial policy and conditions in the world's colonies in kaleidoscopic but ever instructive form. The literature of colonization is elaborate, and the students of this subject, in the countries having colonies, numerous, active and thoughtfull ${ }^{32}$.

No era, pues, un estudio dirigido a los académicos, sino una visión de conjunto que podía ser conveniente a «aquellos que desean llegar a sus propias conclusiones». Uno de esos hipotéticos destinatarios fue William Howard Taft (1857-1930) —al que dedicó un ejemplar de su puño y letra «With the kind personal regards and best wishes»-, gobernador provisional de Filipinas, entonces ocupadas por los soldados norteamericanos. Luego fue Secretario de la Guerra (1904-1908), bajo el presidente Teodoro Roosevelt, al que sucedió en la presidencia de los Estados Unidos (1907-1913). No sé si Taft leyó el grueso volumen, pero se le atribuye ser el gestor de la diplomacia del dólar, hermana gemela de la diplomacia de las cañoneras, prácticas afines a las escuetas premisas imperiales de Austin. Taft creía que el capital norteamericano era el mejor vehículo de progreso. Estaba convencido que las instituciones y las inversiones norteamericanas traerían la ilustración a las áreas no industrializadas del mundo. Bajo su presidencia, Estados Unidos intervino en la República Dominicana, Honduras y Nicaragua ${ }^{33}$.

Sin rodeos, Austin alertó sobre la dependencia de los Estados Unidos de los trópicos, para conseguir el 40 por ciento del total de sus importaciones. De éstas dependían en gran medida la alimentación y las industrias manufactureras, dada la demanda continua de una población con un consumo creciente. Por eso destacó las ventajas de controlar gobiernos y economías tropicales.

1. Asegura la provisión estable y segura de los productos, hijos del capital invertido por la madre patria. El capitalista «inver-

32 Ibid., pp. 1330-1. Los historiadores y testimonios citados, así como la larga y variada bibliografía final en diferentes idiomas, atestiguan el extraordinario ímpetu de este educado imperialista.

33 El libro pionero sobre el tema es de Joseph FreEman y Scott NEARING, Dollar Diplomacy. New York, Monthly Review Press, 1966. La primera edición es de 1925. WILSON [16], p. 815 .

R. I., 1997, n. ${ }^{\circ} 211$ 
tiría su dinero... más fácilmente en un territorio controlado por su propio gobierno que en otra parte. La cuestión de la permanencia del gobierno y por ende de la seguridad de la inversión es una de las primeras a ser considerada por el capitalista inversionista, y esto es ilustrado por el lento desarrollo de la producción a través del capital invertido en las áreas tropicales de Centro y Sur América, donde frecuentes revoluciones y cambios de gobierno tornan inseguras tales inversiones e inciertas las ganancias».

2. Garantiza más, mejores y confiables comunicaciones. Además, los artículos producidos con capital metropolitano van directos del productor al consumidor, sin intermediarios locales que encarecen el precio final.

3. Inyecta «empeño, energía e inventiva», típicas de los ciudadanos de zonas templadas, tal como se constata en las colonias británicas del Lejano Oriente y las Aniillas.

4. La colonia tropical será una consumidora permanente de alimentos y manufacturas de la economía septentrional. Austin no vislumbraba grandes inversiones industriales en los trópicos porque no era fácil conseguir mano de obra estable y diestra; además, creía que el clima deterioraría las máquinas ${ }^{34}$.

\section{AUTONOMÍA PARA LA DEPENDENCIA}

Esas cuentas galanas sobre las ventajas de las colonias directas dependían de la aplicación del mejor método de gobernar y desarrollar las colonias y sus gentes. Austin lo encontró en el sistema colonial británico porque ofrecía un amplio autogobierno. El gobernador era nombrado por la metrópoli, pero las leyes y el poder legislativo quedaban en manos de los habitantes de las colonias, aunque en determinados casos algunos funcionarios eran electos y otros designados por la Corona ${ }^{35}$. Los detalles quedaban en manos de los nativos bajo la supervisión de los representantes metropolitanos. Esta nueva maquinaria no pesaría sobre las arcas de la metrópoli porque los fondos para

\footnotetext{
34 Ibid., pp. 1391-2.

35 Ibid., p. 1464.
} 
sostenerla surgirían de las aduanas o de la tierra dada en usufructo. Lo fundamental era que las colonias enjugaran todos sus gastos ${ }^{36}$.

En el plano económico, la clave residía en el fomento de las comunicaciones de todo tipo, facilitadoras del intercambio económico con el exterior y el país dominador, sin tarifas onerosas. Así se acrecentaba el poder adquisitivo de los habitantes autóctonos y, por consiguiente, «el deseo de las comodidades y las conveniencias de la civilización», como mejores viviendas, educación, periódicos, escuelas, iglesias y mayores poderes para autogobernarse. El colono adquiría nuevos hábitos de industriosidad y frugalidad y la mano de obra local sería suficiente para satisfacer las necesidades de la colonial. La autonomía política garantizaría su rentabilidad económica.

\section{MIRAR PARA DOMINAR}

«Toda ciencia sería superflua si la forma de las apariencias de las cosas coincidiera directamente con su esencia».

Marx

En el afán de clasificarnos, de asignarnos un nivel en la escala de la evolución humana, política, social y cultural, compitieron varias visiones. El espectro es demasiado amplio para examinarlo en este espacio, pero se extendió desde los crudos prejuicios del general George W. Davis hasta el anexionismo ilustrado de Henry K. Carroll $^{37}$. Algunos, la mayoría, mostraron un genuino interés científico y sinceras simpatías por la geografía, los recursos naturales, el potencial económico y por los candidatos a ciudadanos americanos del territorio añadido.

Otros, por el contrario, buscaban lo picturesque y lo diferente, pues sus escritos estaban destinados al público norteño, ávido de fotos y aventuras inéditas de la nueva frontera colonial. No les interesaba lo normal, es decir, las semejanzas con los estilos de vida norteamericanos, sino magnificar lo chocante y lo bizarre. Entre los que cayeron en esta tentación destacó Our Islands and their Peo-

\footnotetext{
36 Ibid., p. 1408.

37 Ver la larga lista de artículos y libros publicados durante los primeros años de la denominación norteamericana en Antonio S. PEDREIRA, Bibliografia puertorriqueña (14931930). Madrid, Imp. de la Librería y Casa Editorial Hernando, 1932, pp. 10-7 y 449-68.
}

R. I., $1997, \mathrm{n}^{\circ} 211$ 
$p_{l} e^{38}$. Por eso es preocupante tomarla como representativa de la construcción del otro puertorriqueño y del discurso colonial norteamericano ${ }^{39}$. Los norteamericanos nunca hablaron con una sola voz, aunque todas las voces hablaron con un solo propósito: el máximo aprovechamiento de la pintoresca posesión. Resulta confuso, por ahistórico, aislar una visión y tomarla como representativa de un abanico de mentalidades y sensibilidades. Si los intereses envueltos (comerciales, financieros, religiosos, navieros, azucareros, militares, científicos, entre otros) eran diversos, complejos y contradictorios, así debió ser también el proceso de estructurar una política colonial y una definición del colono.

La hoja profesional de los participantes del proyecto de Our Islands..., militares de carrera y funcionarios de gobierno durante buena parte de sus vidas, revela el trasfondo de sus miradas. José De Olivares, el redactor principal, nació en la California norteamericana (1867) y sirvió en la Marina y la Reserva Naval de los Estados Unidos (1886-1898). Posteriormente fue cónsul americano en varios países $^{40}$. El texto general es precedido de la bendición marcial contenida en la introducción del mayor general Joseph «Fighting Joe» Wheeler (1836-1906). Éste se graduó de West Point (1858), e ingresó al ejército, del que renunció al estallar la guerra civil (1861) para unirse a la caballería del ejército sureño confederado, en el que ascendió a teniente general. Al terminar la guerra se dedicó al comercio, a la siembra de algodón y a la abogacía. Fue electo al Congreso de los Estados Unidos (1885-1900) y al reventar la guerra hispanocubano-norteamericana se ofreció de voluntario y fue nombrado mayor general. En Cuba presidió exitosamente la batalla de las Guásimas y luego pasó a las Filipinas (1899-1900)41. «Fighting Joe» nunca estuvo en Puerto Rico. El editor tal vez pensó que sus credenciales militares y políticas le daban autoridad para opinar sobre las buenas intenciones de la política exterior norteamericana y, de paso, prestigiaba su publicación.

\footnotetext{
38 BRIAN [28].

39 Ver Lanny THOMPSON, Nuestra Isla y su gente. La construcción del «otro» puertorriqueño en Our Islands and their People. Río Piedras, Centro de Investigaciones Sociales y Departamento de Historia de la Universidad de Puerto Rico, 1995.

40 Ibid., pp. 10 y 64.

41 BEEDE [14], pp. 595-6; Webster's American Military Biographies. Massachusetts, G \& C Merriam Company, 1978, p. 475.
} 
Las mentalidades de estos dos socios de la pluma las delatan dos muestras de su refulgente repertorio retórico. Por ejemplo, el mayor general Wheeler recalca que la «raza» americana se caracteriza por el espíritu de libertad, el amor a la justicia y el trato justo y fue este espíritu el que los lanzó a la guerra contra España, «la guerra por la humanidad». Para consuelo de los conquistados, «este mismo espíritu guiará nuestros tratos con las tribus y las gentes que han recibido la libertad como consecuencia del último conflicto» ${ }^{42}$.

De Olivares fue más terrenal, pero no menos prepotente. Recordemos que, junto al geólogo Hill, nos renombró «Porto Rico» como para asegurar por el rebautizo lo logrado por las armas. En esa vena, su recuerdo de «un día en San Juan» lo llevó a concluir que el rasgo saliente de la ciudad y sus habitantes era —en palabras del caballero criollo que lo acompañaba - la «excelsa indolencia» o, en su propia traducción, la «sublime vagancia»:

A todo lo largo y ancho de la ciudad se recalca y personifica el elemento lánguido y sedentario... Es inescapable encontrar los mismos tipos invariables de una laxitud inherente - las mismas costumbres y condiciones apáticas cristalizadas siglo tras siglo de observancia inviolable.

El ciudadano promedio de San Juan es un silencioso pero elocuente exponente del sonambulismo habitual. Parece estar envuelto perpetuamente en un sueño. A veces pienso que sus horas ambulatorias son más relajadas porque entonces no necesita ni soñar que tiene que trabajar. En el curso de mi visita tuve la ocasión de preguntar a un cierto descendiente de esta aristocracia despreocupada, cuál era el costo más violento de sus esfuerzos, y me comentó con un toque de genuina tristeza: «acostarme en la noche y levantarme en la mañana ${ }^{43}$.

Según él, las masas empobrecidas trabajaban más, pero se conformaban con el menor esfuerzo, recordándonos la estampa idílica del «indolente» campesino puertorriqueño descrita por fray Iñigo Abbad en el siglo XVIII.

Es evidente que lo que para el californiano era una tara moral (prueba de la inferioridad de los súbditos de las antiguas colonias españolas), no era más que el contraste entre el ritmo de trabajo y de la vida en pueblos tropicales de economías agrarias pre-capitalistas y

\footnotetext{
42 BRYAN [28], I, p. 1.

43 Ibid., pp. 257-8 y 260.
}

R. I., 1997, n. ${ }^{\circ} 211$ 
el tempo febril de la existencia cotidiana en la ciudad industrial moderna. Ahora bien, esta aclaración es insuficiente si olvidamos que la distorsión del visitante no era privativa del «otro» imperialista porque la clase propietaria criolla y peninsular solía ver con esos mismos ojos a la mayoría de los jornaleros del país. Las quejas -y las leyes- contra la vagancia fueron una constante de la retórica y la acción de los hacendados y de los que miran a los campesinos desde la ciudad. Para muestra basta la opinión de Fernando López Tuero circulada en 1891:

El temperamento del obrero y del jíbaro es rebelde al trabajo y se presta poco al progreso, el clima le hace indolente y como no tiene necesidades, ni se afana, ni se esmera; es calmoso, abandonado, exigente, y con una idiosincracia tan singular que es preciso tomar bien el pulso a cualquier negocio antes de emprenderlo ${ }^{44}$.

El discurso imperial sencillamente cabalgó sobre el discurso criollo para recordar la inferioridad del «desganado» puertorriqueño frente al industrioso y pujante norteamericano y, por añadidura legitimar su doble sujeción.

Es decir, la hegemonía del dominador de turno fue preparada de antemano por los mismos subalternos (propietarios o educados) de las capas superiores criollas. Es desmayante, por mencionar una de tantas expresiones derrotistas y elitistas, que Luis Muñoz Rivera proclamara en 1891 la indefensión absoluta de los puertorriqueños frente a España, al señalar «las causas del mal» del país: «carecemos de fuerzas populares, por la ignorancia de la población campesina; carecemos de juventud militante por la apatía y el laissez faire de nuestros jóvenes; carecemos de personalidades ricas, porque esos temen mucho a la política romántica y se inspiran en un egoísmo imperdonable.» ${ }^{45} \mathrm{Al}$ año siguiente de la invasión, Manuel Fernández Juncos le confesó al comisionado Carroll que la principal falta de los puertorriqueños era la «ausencia de voluntad» ${ }^{46}$. El invasor no tuvo

44 Fernando LóPez Tuero, La reforma agrícola. Puerto Rico, Tipografía del Boletín Mercantil, 1891, p. 22.

45 Luis MuÑoz Rivera, «Las causas del mal» (V), en Campañas políticas (18901900). Madrid, Editorial Puerto Rico, 1925, 3 vols., I, p. 39.

46 Henry K. CARroll, Report on the Island of Porto Rico. Washington, Government Printing Office, 1899, p. 36. 
que devaluarnos para dominarnos porque ya estábamos desmerecidos por los grupos dirigentes y pensantes del país. En ese, como en otros terrenos, los norteamericanos ganaron la guerra antes de la guerra. Es peligroso, por consiguiente, construir la identidad del colono a través de la diferencia porque no toma en cuenta las semejanzas entre los otros y nosotros, antes y después de «la llegada».

Sería exagerado concluir que los norteamericanos no tomaron a Puerto Rico porque simplemente se lo dimos. Pero es claro que le facilitamos la ingestión. Ante el apabullante poder de los Estados Unidos -y la ridícula e irresponsable resistencia española - muy poco podía hacer el liderato del país que aún bajo el viejo régimen desconfiaba de la capacidad combativa del pueblo. Desvalidos ideológica y militarmente, jugaron la carta del realismo político. Muñoz Rivera no perdió tiempo y les sugirió el «método más sencillo y más fácil para americanizar a Puerto Rico», cuando un periodista le preguntó si la isla era capaz de autogobernarse como los estados de la Unión americana:

Opino que mi país puede gobernarse y administrarse a sí propio, y que a eso aspira la totalidad de los criollos. Hay elementos directores competentísimos y hay pueblo dócil y sensato que le secunda. El deseo general puede condensarse en esta fórmula: la ocupación militar, breve, muy breve, prolongándose mientras se reúne el parlamento en Washington: durante la ocupación militar las leyes que hoy rigen y los organismos que hoy funcionan deben respetarse: después, enseguida, la declaración de territorio, con una legislación adaptable a la legislación nacional; pero nunca menos autonómica y libre que la que poseemos: más tarde, en un corto plazo, la declaración de Estado que colmaría los anhelos del país y le identificaría por completo con la nueva patria. Tal es el método más sencillo y más fácil para americanizar a Puerto Rico ${ }^{47}$.

EL PAÍS REAL

«No se trata de una sociedad que domina a otra preexistente, sino de una sociedad que se relaciona con otra en constitución.

\footnotetext{
47 «Interview de Luis Muñoz Rivera siendo secretario de Estado en octubre de 1898 con un representante del New York Tribune», En Cayetano Coll y Toste, ed., Boletín Histórico de Puerto Rico. San Juan, Tipografía Cantero Fernández y Cía, 1914-1927, 14 vols., XIII, pp. 342-5. El subrayado aparece en el original.
}

R. I., 1997, n. ${ }^{\circ} 211$ 
En cierta forma... el nexo colonial es creado al mismo tiempo que por la metrópoli por la sociedad implantada...»

Germán Carrera Damas

El análisis del colonialismo a partir de «los símbolos y las narrativas del imperialismo estadounidense», reforzado por las fotografías, como agentes del «contraste entre lo primitivo y la civilización», es necesario y fructífero ${ }^{48}$. Mas, en ausencia de otra evidencia, privilegia la representación (el discurso o las fotos) sobre otras actividades humanas. Al no compararse lo que se dice con lo existente, las realidades discursivas acaparan la atención y se olvidan o pasan a un plano insignificante, las realidades no discursivas ${ }^{49}$.

El puertorriqueño, antes de ser súbdito norteamericano o tema de sus representaciones escritas y gráficas, era peón explotado, negro discriminado, artesano censurado, criollo vigilado, exiliado o privado de derechos parejos al del español. La sociedad que el invasor encontró en el 98 era monárquica, racista y colonial, condicionada por el sistema capitalista internacional. Por lo tanto, sería un error «...ver el nexo colonial como algo existente fuera de las propias sociedades implantadas latinoamericanas ${ }^{50}$.

El Puerto Rico de fines de siglo era el resultado de la larga y honda articulación de imposiciones y dominaciones que desembocaron en unas estructuras económicas y sociales desiguales e injustas, y en la inferioridad política de los isleños ante la Corona española. Las luchas por superar estos escollos le imprimieron movimiento a la historia del país, pero el forcejeo por lo alto, por conquistar derechos políticos secuestrados, expresado ordinariamente como un choque entre el criollo y el peninsular, era sólo un ángulo del rostro colonial. El otro perfil mostraba el ingenio, las tretas y los sacrificios de los campesinos y los artesanos para aliviar y burlar el dominio indiscriminado de criollos y españoles en la hacienda y el taller. En la patria del criollo, esbozada en las producciones literarias y en los escritos políticos, los trabajadores del campo y la ciudad jugaban pape-

48 ThOMPSON [39], pp. 5, 13 y 61.

49 El planteamiento es de Aijaz AHMAD, In Theory. Classes, Nations, Literature. London, Verso, 1994, p. 182

50 Germán CARRERA DAMAS, Una nación llamada Venezuela. 4. ${ }^{a}$ ed., Caracas, Monte Avila Editores, 1991, p. 38. 
les secundarios como recipientes obedientes y agradecidos del ilustrado paternalismo de hacendados e intelectuales ${ }^{51}$.

El paradigma civilización y barbarie de Wheeler, Bryan, De Olivares y otros no vino del frío, pues los tropicales señores de la tierra, el comercio y las letras, lo habían estrenado antes y lo perpetuaron después del 98. Muñoz Rivera lo expresó sin dobleces frente al comisionado Carroll al oponerse a rebajar la edad de votar a 21 años: en vista de que «la raza latina es exitable e irreflexiva... sería extremadamente peligroso colocar nuestro futuro en manos de las masas que carecen de educación cívica y que pueden ser erróneamente dirigidas por agitadores audaces que los convertirán en sus títeres» ${ }^{52}$. Esta apreciación es casi un calco de la expresada por el general George W. Davis, uno de los gobernadores militares, al favorecer el sufragio restringido de los puertorriqueños.

If universal or manhood sufrage be given to the Puerto Ricans, bad results are almost certain to follow. The vast majority of the people are no more fit to take part in selfgovernment than are, our reservation Indians, from whom the suffrage is withheld unless they pay taxes. They certainly are far inferior in the social, intellectual, and industrial scale to the Chinese, who for very good reasons are forbidden to land on our shores. The ignorant masses will be manipulated and controlled and corrupted by the political bosses ${ }^{53}$.

\section{TERRITORIO Y AUTOCRÍTICA COLONIALES}

«... Lo que el realismo crítico exigía era que la crítica de los otros (el anticolonialismo) se hiciera desde la perspectiva de la crítica de nosotros, más comprensiva y multifacética: nuestra estructura de clases, nuestras ideologías familiares, nuestros manejos de los cuerpos y las sexualidades, nuestros idealismos, nuestros silencios.»

\section{Aijaz Ahmad}

\footnotetext{
$51 \mathrm{Al}$ respecto ver los comentarios de Mariano M. NEGRón al texto de Thompson en Notas de Investigación Social. Centro de Investigaciones Sociales, núm. 3, nov. 1995, p. 4.

52 Carroll [46], pp. 235-6.

53 George W. DAVIS, «Military Government of Porto Rico, From October 1898 to april 30, 1900», Annual Report of the War Department fot the Fiscal Year Ended June 30, 1900. Part 13. Report of the Military Governor of Porto Rico en Civil Affairs. Washington, Government Printing Office, 1902, pp. 114-6.
}

R. I., 1997, n. $^{\circ} 211$ 
La premisa de que los norteamericanos nos inventan, nos orientalizan, les niega su capacidad para conocernos, para añadir conocimiento. Este es el caso de la crítica de Thompson a la imprecisión y la ambigüedad de los juicios y las fotos del redactor turista De Olivares, sobre los criollos y los peninsulares, los indígenas y los mulatos. En primer lugar, se trata de zonas de conflicto, endemoniadamente borrosas de nuestro pasado y nuestro presente. El que un recién llegado concluya que había «dos clases de españoles» no obedecía necesariamente al deseo de borrar al criollo. Los puertorriqueños eran ciudadanos españoles y el modelo de la elite autóctona blanca era el señor español con el que muchos deseaban confundirse, por prestigo y afinidad cultural. Olivares, un ave de paso, parece identificar lo español con lo superior, pues da la impresión que usa el gentilicio «español» como categoría racial y clasista para identificar la clase alta blanca y no como un recurso para sacar al criollo de la historia ${ }^{54}$.

Por otro lado, si éramos y somos un revolú étnico, social y político, una sociedad de inmigrantes que se mezclan incesantemente, en una colonia que era oficialmente una «provincia», ¿por qué sorprendernos que en Our Islands... «la identidad de los puertorriqueños no se presenta de forma unitaria o coherente sino que expresa diferentes perspectivas, tensiones, dudas y contradicciones ${ }^{55}$. En una Isla donde se violenta el lenguaje y se tuerce la razón al tratar de distinguir entre mulato, trigueño, pardo y moreno no es extraordinario que un visitante llegue a conclusiones imprecisas y contradictorias, sin que concluyamos que nos inventa para inferiorizarnos.

De la misma manera, si en las fotos y el texto «se presenta a los puertorriqueños como mulatos a la vez que se desplaza la negritud de la población a través de un énfasis en el pasado indígena y un posible blanqueamiento» ${ }^{56}$ eso no significa, inequívocamente, una

\footnotetext{
54 Es lo que hace Robert T. HILl al referirse a «The Porto Rican Spaniards, this class of white blood and Spanish feelings» como sinónimo de la capa dominante criolla. Cuba and Porto Rico with other Islands of the West Indies. New York, The Century Co., 1898, p. 166. C. H. RECTOR, otro de los tantos visitantes, concluyó también que "the Spanish and native Porto Rican are not distinguishable to en American eye". The Story of Beautiful Porto Rico. A Graphic Description of the Garden Spot of the World by Pen and Camera, Chicago, Laird \& Lee, Publishers, 1898, pp. 46-50.

55 THOMPSON [39], p. 30.

56 Ibid., pp. 45-6.
} 
negación de la cultura puertorriqueña o de nuestra negritud, sino el reconocimiento de que los negros y sus mezclas eran centrales en nuestra cultura. Sin decirlo, ¿no será una de las cosas que quiere recalcar el visitante y que quería ocultar el criollo blanco? La impresión fotográfica de que éramos un país mestizo debió quemar las delicadas retinas de los encopetados de la época. El intento de muchos negros y mestizos puertorriqueños de aindiarse para salvar el humillante prejuicio racial, no es más que la confirmación de cuán traumática fue la aceptación de la identidad propia y cuán difícil debió ser su comprensión para el extranjero recién desembarcado.

Por otro lado, la profusión de fotos de negros y mulatos, mujeres y niños, en vez de disminuir la cultura puertorriqueña la amplía -a pesar de los indiscutibles prejuicios de los autores- al incluir los sectores subordinados que constituían la mayoría de la población. Además, representaban lo diferente, la heterogeneidad real frente a la ilusoria homogeneidad. Lo representativo no eran los blancos sino los mestizos. Esa era nuestra originalidad respecto a la sociedad norteamericana, de la que procedía el redactor y para la que escribía sus reportajes.

RECAPITULACIÓN: EL 98 NO EXPLICA EL 98

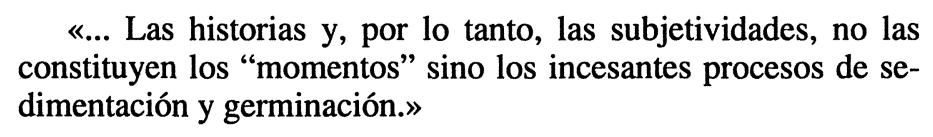

Aijaz Ahmad

Las conmemoraciones siempre nos tientan a congelar el momento recordado y a olvidar su pasado. El 98 no es una excepción y más si el presente nos lo recuerda a cada paso. Por lo tanto, es inescapable y debemos lidiar con él. Pero nunca podremos exorcisarlo si seguimos atrapados en la rígida dicotomía del vencedor y el vencido, sin terrenos compartidos. De ahí la importancia de desvelar nuestros silencios a la vez que criticamos las imposiciones coloniales. Así, el criollo no sólo es víctima sino también victimario y cómplice, autónomo e insubordinado ante los extremos del poder imperial. Ese desplazamiento constante entre la complicidad y la resis-

R. I., $1997, \mathrm{n}^{\circ} 211$ 
tencia es la contradicción dinámica, problemática y creadora de nuestra existencia isleña.

La guerra del 98 nos colocó en el duro dilema de pelear junto a España contra el primer mercado consumidor de nuestro azúcar, del que importábamos buena parte de las manufacturas y los comestibles. Al interés comercial se sumó el estratégico-militar, por lo que no sorprende que los Estados Unidos jugaran un papel decisivo en los dos éxitos principales del liberalismo puertorriqueño del siglo XIX: la abolición de la esclavitud (1873) y la concesión de la autonomía (1897). En ambas coyunturas, los norteamericanos forzaron el desenlace con el fin de sofocar sendos focos de intranquilidad que atentaban contra la estabilidad política y económica norteña. El comercio de mercancías fue también de la mano del comercio de ideas. Igual que en el resto de América Latina, los Estados Unidos fueron un modelo económico, político y social. En algunos casos, como en el de Cuba, Puerto Rico y la República Dominicana, la admiración se tornó en deseo de anexión.

La historia del anexionismo en Puerto Rico ha sido tan difícil de rastrear como la de los obreros, las mujeres y los negros. A la dificultad de la falta de documentos fáciles, a flor de tierra, se suma el temperamento de algunos historiadores nacionalistas y autonomistas que prefieren pesquisar lo patriótico en desmedro de lo «claudicante». Pero la realidad, en este caso, la estrecha relación económica con Estados Unidos y la torpe política colonial española, es terca y termina por imponerse. Así, Alexandre Lafont de la Vernese, cónsul de Francia en Puerto Rico, le comunicó al Ministerio de Relaciones Extranjeras de París, en 1865: «Me crucé hace algunos días con comerciantes honorables y ricos hacendados. Están convencidos que las colonias españolas serán anexadas a los Estados Unidos y lejos de temer esa anexión la consideran como una fuente de prosperidad para Puerto Rico. Esa es la opinión dominante en el país; se está convencido de que el gobierno debe organizarse para el bienestar general y la prosperidad del comercio, y que un gobierno equitativo que asegure a los ciudadanos la igualdad ante la ley, debe ser el fin de sus deseos» ${ }^{57}$. Ocho años después, el cónsul Le Brun confirmó la persistencia de la corriente anexionista: «...Si me preguntan mi opinión

57 Centro de Investigaciones Históricas. Correspondencia consular de Francia, rollo 3, tomo 6, 25 de septiembre de 1865, folios 253-4. La traducción es mía. 
diría que Puerto Rico no parece en estado de oponer una seria resistencia a los Estados Unidos y que si los norteamericanos desembarcaran en la isla encontrarían amigos muy dispuestos a acogerlos.» ${ }^{58}$

Perseguido como el independentismo, el anexionismo se hizo clandestino o emigró al Norte donde a fines de siglo germinó en la Sección Puerto Rico del Partido Revolucionario Cubano. Del sedimento que quedó en la isla, brotaron en 1898 varias cuadrillas anexionistas con nombres chillones como «Porto Rican Scouts»y «Porto Rican Guard» que se dedicaron a ocupar municipios y a hostigar los soldados españoles en varios pueblos del centro y el oeste del país. «En todos estos lugares — señala Mariano Negrón Portillo- las mismas actuaron como representantes de los Estados Unidos y trataron de asumir control de los pueblos para facilitarle a las tropas norteamericanas la consolidación de su poder, con el mínimo de problemas.» ${ }^{59}$

Derrotados los españoles y consolidado el nuevo poder norteamericano, los dos partidos políticos autonomistas se hicieron anexionistas y proclamaron la esperanza de ser estado de la Unión. Hasta los inconformes con el prolongado régimen militar, le comunicaron al Congreso norteamericano en 1900: «Puerto Rico, antes la joya de la Corona de España, será una estrella prometedora y acaso en día futuro fija permanentemente en el azul de la bandera que vino a traerle la libertad y protección y los leales puertorriqueños bajo ella, vivirán satisfechos y si necesario fuese morirían orgullosos.»60

En los albores de la nueva dominación, cuando el deseo entusiasmado de la mayoría era disfrutar las ideas democráticas del gobierno norteamericano, parecía que Puerto Rico no era un problema, como creía el Secretario de la Guerra Root. Para él era indiscutible la potestad plenaria de los Estados Unidos porque era una nación con todos los derechos sobre el territorio. Pero sus habitantes no

\footnotetext{
58 Centro de Investigaciones Históricas. Correspondencia consular de Francia, rollo 4, tomo 8, 12 de diciembre de 1873, folio 370 (reverso). La traducción es mía.

59 Mariano Negrón PoRTILlo, Las turbas republicanas 1900-1914. Río Piedras, Ediciones Huracán, 1990, pp. 34 y ss.

60 Entre los firmantes de esta declaración sobresalen Manuel Fernández Juncos, José Julio Henna, Tulio Larrínaga y Luis Sánchez Morales. «Memorial de protesta y petición del pueblo de Puerto Rico al Congreso de los Estados Unidos». 24 de febrero de 1900, en J. J. Henna y M. Zeno Gandía, El caso de Puerto Rico. Tr. de Alberto Ruiz y P. J. Besosa, New York, Imprenta de A. Lallemand \& Co., 1917, p. 80.
}

R. I., 1997, n. $^{\circ} 211$ 
podían reclamar ser tratados como miembros de los estados o de los territorios previamente tomados por la nación norteamericana. Sin embargo, tenían el derecho moral a ser tratados de acuerdo a los principios de justicia y libertad de la Constitución estadounidense ${ }^{61}$.

Root confundió la esperanzada aceptación popular de los invasores con la simpleza del caso puertorriqueño. Nunca imaginó que la pronta insatisfacción de los isleños, espoleada por el deterioro de la economía y por la negación de poderes que a regañadientes España había cedido en 1897 -sumada al fuerte mestizaje boricua- desataría una enredada discusión y una trabajosa «construcción legal» de Puerto Rico y los puertorriqueños ${ }^{62}$.

Por un lado, el Congreso norteamericano armó un gobierno colonial amparado en la Ley Foraker (1900), con gobernador y Consejo Ejecutivo nombrados por el presidente de los Estados Unidos, y reclamó la última palabra respecto a los asuntos del país conquistado. Al poder congresional, se sumó el judicial, pues la Corte Suprema de los Estados Unidos era también la de la colonia. Artillada con vastas prerrogativas legales, la Corte Suprema trazó las líneas políticas centrales del territorio tropical.

A través de los famosos «casos insulares» (1901-1922) la Corte Suprema norteamericana terció en el debate entre los imperialistas y las dos versiones antianexionistas (la racista, que se negaba a incorporar gentes inferiores, y los que creían que una vez obtenidos los territorios no habría más remedio que extender a sus habitantes la protección de la Constitución). El arreglo final, el invento que no frustró otros artefactos jurídicos imperialistas, fue sancionar el proyecto colonial mediante la legalización del dominio sobre la preciada presa $\mathrm{y}$, paralelamente, conceder a los nativos los típicos derechos constitucionales. Ante el cuestionamiento de la legitimidad del proyecto colonial, los jueces del Supremo confeccionaron una doctrina legal que justificó el ejercicio de poderes casi irrestrictos sobre los territorios y las gentes adquiridos en la guerra del 98 . En el proceso, hornearon una diferencia, desconocida hasta entonces, entre territorios incorporados (los llamados «estados infantiles») y territorios

61 RoOT [3], pp. 161-2.

62 Efrén RIVERA, «The Legal Construction of American Colonialism: The Insular Cases (1901-1922)», Revista Jurídica de la Universidad de Puerto Rico, vol. 65, núm. 2, 1996. 
no-incorporados (propiedad de, pero no parte de los Estados Unidos) y dieron al Congreso y al presidente la mayor laxitud para confeccionar e implantar sus cambiantes políticas expansionistas ${ }^{63}$.

Es decir, desde el inicio, Puerto Rico fue un problema que provocó miradas cruzadas y contradictorias. Por eso, a la óptica de Our Islands se sumaron otras más equilibradas. Robert T. Hill, por ejemplo, apuntó que la geografía y la gente de la Isla no podían verse a través de las costumbres y el medio ambiente tradicionales. Reconoció que su país no era un adecuado criterio de comparación con las gentes y los territorios del Mediterráneo americano. Proponía que en vez de amalgamar a todos los pueblos del Caribe en una clasificación uniforme e indiscriminada, se debía destacar su singularidad ${ }^{64}$. Hill tampoco «elimina a la clase dominante criolla» 65 . Por el contrario, destaca su abolengo, su orgullo étnico y su opulencia, y señala que son diferentes a sus pares de las islas francesas y británicas ${ }^{66}$.

Mas ninguno de los testimonios elogiosos del momento comparan en amplitud, inteligencia y sensibilidad con el de Henry K. Carroll. En dos largas visitas hechas a fines del 98 y comienzos del 99 , recogió testimonios y vio con sus propios ojos algunas de las zonas más críticas y relevantes de la sociedad puertorriquena. Hizo un inventario del clima y la agricultura, la tolerancia religiosa y el anticlericalismo, la indefinida frontera entre la propiedad pública y la eclesiástica, el analfabetismo, las comunicaciones, el concubinato y los hijos ilegítimos, las condiciones de vida de los trabajadores y el carácter y las aspiraciones de los puertorriqueños.

Armado con un sólido conocimiento del país, Carroll nunca puso en duda los atributos y la capacidad de los puertorriqueños para estar a la altura de los norteamericanos. En la defensa del derecho de los nativos al «self-government», no ocultó el analfabetismo dominante y la inexperiencia en las prácticas políticas democráticas. Pero insistió en que la educación y la experiencia no hacen, necesariamente, buenos ciudadanos. Además, estaba convencido de que nadie tiene el derecho a decidir quién da la talla para autogobernarse ${ }^{67}$.

\footnotetext{
63 Ibid., pp. 326-7.

64 HILl [54], pp. XXII-XXIII.

65 Es la omisión que THOMPSON le reprocha, equivocadamente, a Our Islands [39], p. 27.

66 HILl [54], p. 166.

67 Carroll [46], pp. 56-8.
}

R. I., 1997, n. $^{\circ} 211$ 
Por consiguiente, recomienda sin reservas que Puerto Rico se convierta en un territorio con gobierno propio, similar al de Oklahoma, con el gobernador y los miembros de la rama ejecutiva nombrados por el presidente de los Estados Unidos, y una rama legislativa bicameral electa por el voto popular. Este sistema descansaría sobre la educación obligatoria y el respeto a la lengua y los usos y costumbres de los puertorriqueños, así como en el sufragio masculino, sin requisitos de literacia o propiedad ${ }^{68}$. Esta receta reflejaba, según Carroll, las esperanzas de los puertorriqueños respecto a los norteamericanos.

Ellos esperan que bajo la soberanía norteamericana se corrijan los males centenarios; que tengan un gobierno honesto y eficiente; la más amplia libertad como ciudadanos de la gran República bajo la Constitución; gobierno propio provisto por el sistema territorial; libre acceso a los mercados de los Estados Unidos; la adopción del idioma inglés a su debido momento y la adaptación general de la isla a todas las instituciones que han contribuido a la prosperidad, el progreso y la felicidad del pueblo americano ${ }^{69}$.

Algunas de estas aspiraciones se han logrado y otras han cambiado de tono o han sido redefinidas, pero la relación cercana con los Estados Unidos es todavía el vivo anhelo de la mayoría de los puertorriqueños. El anexionismo de las dos caras (autonomista y estadista, una distinción sin una diferencia) sigue valorando la ciudadanía y el mercado común e insiste en la identidad criolla y en la dignidad compartida con los estadounidenses.

Esa relación íntima, cada vez más próxima, similar a la que tuvimos con España, tiene una «...historia de encuentros y desencuentros, de opresión y resistencia, de apropiaciones mutuas, de negociación de espacio...» ${ }^{70}$ En la confusión de la derrota española y el remolino de esperanzas de la victoria americana - sobre todo la oportunidad de volver a ser gente- los niveles inferiores se desatan y se aúpan, asustando a los propietarios y los profesionales. El miedo a las capas populares dislocadas, los une y los concita y hacen

\footnotetext{
68 Ibid., pp. 56-65.

69 Ibid., p. 56. La traducción es mía. p. 147.

70 Arcadio DíAZ QuiÑonEs, La memoria rota. Río Piedras, Ediciones Huracán, 1993,
} 
causa común con el enemigo extranjero (al que le habían declarado la guerra de palabras antes del desembarco), aliado útil para frenar a los licenciosos, a los de abajo, y ponerlos en su sitio.

En la coyuntura del 98, los intereses de clase son más fuertes que los de la nacionalidad y la identidad. Dominador y dominado se funden y se confunden. Los obreros aprovechan la brecha y ven en la anexión la segura subordinación de los propietarios criollos y peninsulares al poder norteamericano, más democrático, laico e igualador. Los propietarios y los profesionales, por su parte, no vieron contradicción entre la autonomía - y el acceso libre al mercado yanquiy la búsqueda del gobierno propio de la región dentro de la Unión americana. Por caminos y motivos diferentes, el anexionismo proletario y el anexionismo autonomista imitan al invasor.

Nuestro pasado español, lastrado de coloniaje, racismo e ignorancia y de una paradójica dependencia del mercado norteamericano, nos hizo un país pret-à-porter, listo para llevar, pero no una nación a la medida americana. Celebramos la derrota del imperio decadente, mas exigimos libertades y poderes, desde los anexionistas molestos, disminuidos por una ciudadanía de caricatura, hasta los nacionalistas y los socialistas rebeldes, enemigos de la colonia moderna presidida por grandes compañías azucareras y gobernadores nombrados desde la cornisa del imperio.

Hoy sería anacrónico concluir que el interés primordial de los Estados Unidos es inferiorizarnos a través de la dominación cultural, porque el capital norteño se ha criollizado y la mayoría de los puertorriqueños se sienten iguales y distintos a los norteamericanos. La identidad puertorriqueña, como todas las identidades, no es algo acabado e inmutable sino una vivencia inconclusa, en constante transformación, contradictoria y compleja, como la vida misma ${ }^{71}$.

En fin, el 98 fue el año de la liberación y la dominación. En la medida en que logremos lidiar con esta incómoda conclusión, reconocer lo positivo en lo negativo del poder avasallador de los Estados Unidos, estrenado un siglo atrás, podremos superar las visiones históricas que nos proyectan como víctimas inermes de la superioridad material y militar, y de las construcciones discursivas imperiales. El

\footnotetext{
71 Ver el replanteamiento de la identidad como un proceso, como una lucha contra sí misma en Perry ANDERSON, «Fernand Braudel and National Identities», Zone of Engagement. London, Verso, 1992, pp. 251-78.
}

R. I., $1997, \mathrm{n}^{\circ} 211$ 
viejo dicho de que uno es lo que uno hace, aplicado al tremendo 98, servirá para calibrar el alcance de la responsabilidad criolla en la entronización pasada y la persistencia presente del gobierno americano sin los americanos. Y valorar críticamente los singulares y desiguales combates boricuas por la justicia social y económica, la cultura y la libertad política. Repensar el 98 desde ese mirador, quizás ayude modestamente a lograr, algún día, la verdadera liberación.

Rethinking «98» in Puerto Rico requires giving up «victimized» perspectives whereby the Porto Rican people are set free of all responsibility. Focusing on 1898 as a year of both liberation and domination, this article weighs up the positive and negative aspects of Northamerican imperialism, while analyzing the unbalanced and particular struggles of the Porto Ricans in the social, economical, cultural and political fields. This process is partly followed through the writhings of Elihu Root and Salvador Brau. 